\title{
Double star induction machine using nonlinear integral backstepping control
}

\author{
Abdallah Abden ${ }^{1}$, A. Bouchetta ${ }^{2}$, O. Boughazi ${ }^{3}$, A. Baghdadi ${ }^{4}$, I. K. Bousserhane ${ }^{5}$ \\ 1,2,3,5 TAHRI Mohammed University, Bechar, Algeria \\ ${ }^{4}$ Djillali Liabes University, Sidi-bel-Abbes, Algeria
}

\begin{tabular}{l}
\hline Article Info \\
\hline Article history: \\
Received Apr 11, 2018 \\
Revised Sep 24, 2018 \\
Accepted Oct 23, 2018 \\
\hline
\end{tabular}

Keywords:

Dual star induction

Field oriented control (FOC)

Integral backstepping

lyapunov function

Machine (DSIM)

Nonlinear control

\section{Corresponding Author:}

Abdallah Abden,

Control analysis and optimization of Electro-energy systems laboratory,

Tahri Mohammed University, Bechar, Algeria.

Email: abdenabd08@gmail.com

\begin{abstract}
This paper presents a nonlinear Integral backstepping control approach based on field-oriented control technique, applied to a Double Star Induction Machine 'DSIM' feed by two power voltage sources. We present this technique of integral backstepping by using reduced and complete mathematical model. The objective is to improve the robustness of machine under internal parameter variation with nonlinear Integral backstepping control. The robustness test results obtained by simulation prove the effectiveness of control with using complete model of DSIM.
\end{abstract}

Copyright (C) 2019 Institute of Advanced Engineering and Science. All rights reserved.

\section{INTRODUCTION}

For many years DSIM have been used in many applications, for their advantages, among others: Minimise the electromagnetic torque and the rotor losses, uses a power electronics component which allows a higher commutation frequency and the improvement of reliability by offering the possibility of operating correctly in degraded regimes (one or more open phases) [1]-[3]. A lot of research has approached the control of the DSIM for more than 20 years, while seeking to have a very good rejection of disruption and good robustness in the face of changing parameters.

In this paper we propose in this article a Backstepping control using the complete mathematical model of the machine, we will then make a comparison of these performances with the Backstepping control using reduced model. we use this technique to design a robust control based on the principle of field oriented control, this new version of backstepping with integral action solves the problem of constant static error and sensitivity to Noise appeared in the classic version of backstepping. The effectiveness of this proposed control structure is verified by simulation using the reduced and complete model of DSIM, with this proposed control, the load disturbance rejection capability is highly improved.

\section{DESCRIPTION OF THE DSIM}

This machine is based on the principle of a double stators displaced by $\gamma=30^{\circ}$. The stators are similar to the stator of a simple induction machine and fed with 03 phase alternating current and provide a rotating flux, each star is composed by three identical windings with axes spaced by $\alpha=\gamma=30^{\circ}[1]-[3],[10]-[12]$. 


\section{MODELLING OF THE DSIM IN (D-Q) REFERENCE}

DSIM with the distribution of its windings and its own geometry is very complex to lend itself to an analysis taking into account its exact configuration, it is necessary to adopt certain simplifying assumptions. In addition to the hypotheses of the generalized machine, it will be assumed that the two stator three-phase windings are balanced and identical (the six phases therefore have the same electrical characteristics) [1]-[3], [11-12].

\section{DIRECT FIELD ORIENTED CONTROL FOR DSIM}

The principle of field Oriented Control strategy is to eliminate the coupling problem between the two direct axes (d) and quadrature (q), which makes it possible to assimilate the asynchronous machine to an independently excited DC machine as its main advantage to be easily controllable. Indeed, the inductor current is a flux generator while the armature current is a torque generator. The FOC consists in making $\varphi_{\mathrm{qr}}=0$ while the rotor direct flux $\varphi_{\mathrm{dr}}$ converges to the reference $\varphi_{\mathrm{r}} *[3]-[5]$.

\subsection{Complete model of DSIM}

The Complete mathematical model of the Double star induction motor can be expressed in the (d-q) synchronous rotating frame by the following nonlinear equations, Taking into account that the rotor of the DSIM is short-circuited [1]-[3].

$$
\begin{aligned}
& \frac{d_{b s+1}}{d t}=\left[V_{d s 1}-R_{z} i_{d s 1}-d_{1} \frac{d \varphi_{\dot{\theta}}}{d t}+\omega_{z}\left[\left(L_{z}+a\right) i_{Q s 1}+a i_{Q s 2}+d_{1} \varphi_{\varphi r}\right]\right]
\end{aligned}
$$

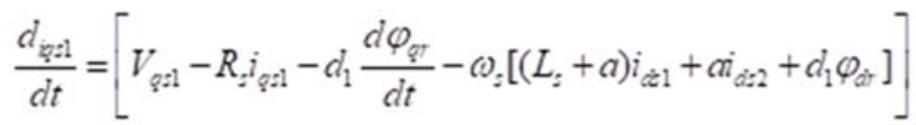

$$
\begin{aligned}
& \frac{d_{i t z 2}}{d t}=\left[V_{\dot{z} 2}-R_{z} i_{d z 2}-d_{1} \frac{d \varphi_{\dot{\partial}}}{d t}+\omega_{z}\left[\left(L_{z}+a\right) i_{q z 2}+a_{q z 1}+d_{1} \varphi_{\varphi r}\right]\right] \\
& \frac{d_{i g s 2}}{d t}=\left[V_{\ll 2}-R_{z} i_{q v 2}-d_{1} \frac{d \varphi_{q r}}{d t}-\omega_{z}\left[\left(L_{z}+a\right) i_{d s 2}+a i_{d s 1}+\left(d_{1}\right) \varphi_{d r}\right]\right] \\
& \frac{d \varphi_{\dot{\alpha}}}{d t}=\left[b_{5}\left(i_{\dot{\alpha} 1}+i_{\dot{\alpha} 2}\right)-b_{6} \varphi_{\dot{d r}}+\omega_{g} \varphi_{\varphi r}\right] \\
& \frac{d \varphi_{\varphi r}}{d t}=\left[b_{5}\left(i_{\xi 1}+i_{\xi=2}\right)-b_{6} \varphi_{\varphi r}-\omega_{g} \varphi_{\text {ir }}\right] \\
& \frac{d \omega_{r}}{d t}=\frac{P^{2}}{J} d_{1}\left[\left(i_{Q: 1}+i_{Q: 2}\right) \varphi_{d t}-\left(i_{d s 1}+i_{d s 2}\right) \varphi_{Q r}\right]-\frac{p}{J} C_{r}-\frac{f c}{J} \omega_{r} .
\end{aligned}
$$

\subsection{Reduced model}

By applying the Field Oriented Control principle to the complete mathematical model (1), we put $\left(\varphi_{\mathrm{qr}}=0\right.$ and $\left.\varphi_{\mathrm{dr}}=\varphi \mathrm{r}\right)$ and the system of equation in $(\mathrm{d}, \mathrm{q})$ for the DSIM in reduced model become [1]-[3]:

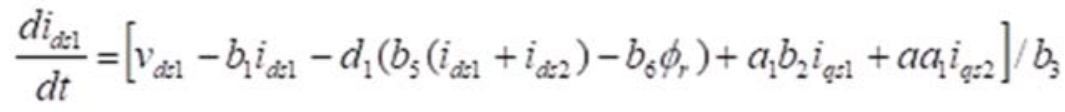

$$
\begin{aligned}
& \frac{d i_{q: 1}}{d t}=\left[v_{q: 1}-b_{1} i_{q v 1}-a_{1} b_{2} i_{d * 1}-a a_{1} i_{d * 2}+a_{1} d_{1} \phi_{r}\right] / b_{3} \\
& \frac{d i_{d: 2}}{d t}=\left[v_{d: 2}-b_{4} i_{d: 2}-d_{1}\left(b_{5}\left(i_{d: 1}+i_{d: 2}\right)-b_{6} \phi_{r}\right)+a a_{1} i_{q t 1}+a_{1} b_{2} i_{q: 2}\right] / b_{3} \\
& \frac{d i_{g: 2}}{d t}=\left[v_{q: 2}-b_{4} i_{q: 2}-a_{1} b_{2} i_{d: 2}-a a_{1} i_{d: 1}-a_{1} d_{1} \phi_{r}\right] / b_{3}
\end{aligned}
$$




$$
\begin{aligned}
& \frac{d \phi_{d r}}{d t}=\left[b_{5}\left(i_{d s 1}+i_{s d 2}\right)-b_{6} \varphi_{d r}\right] \\
& \frac{d \omega_{r}}{d t}=\left[b_{7} \varphi_{a r}\left(i_{q z 1}+i_{q z 2}\right)-b_{8}-b_{9} \omega_{r}\right] \\
& \left(\omega_{z}-\omega_{r}\right)=\frac{R, L_{m}}{\left(L_{m}+L_{r}\right)} \frac{\left(i_{z p 1}+i_{m p 2}\right)}{\varphi_{r}} \\
& J \frac{d \omega_{r}}{d t}=C_{e n}-C_{r}-K_{f} \omega_{r} \\
& C_{e m}=\frac{3}{2} P \frac{L_{m}}{\left(L_{m}+L_{r}\right)}\left(\varphi_{r}\left(i_{q+1}+i_{q 2}\right)\right) \\
& a=\frac{L_{1} L_{m}}{L_{r}+L_{m}}, a_{1}=\omega_{z}, b_{1}=R_{z 1}, b_{2}=\left(L_{s}+a\right) \text {, } \\
& b_{3}=L_{3}, b_{4}=R_{2}, b_{5}=\frac{R_{1} L_{m}}{L_{+}+L_{m}}, b_{6}=\frac{R}{L_{4}+L_{m}}, \\
& b_{7}=\frac{P L_{m}}{J\left(L_{c}+L_{m}\right)}, b_{8}=\frac{C_{r}}{J}, b_{9}=\frac{f_{c}}{J}, d_{1}=\frac{L_{m}}{L_{4}+L_{m}}
\end{aligned}
$$

with: $\omega_{g l}=\left(\omega_{s}-\omega_{r}\right)$

\section{BACKSTEPPING CONTROL}

The basic principle of backstepping control is to make closed loop systems equivalent to first-order subsystems in cascade that are Lyapunov stability, This gives ensures robustness and asymptotic global stability [2], [10], [11].

Our objective is to control the flux and speed variables, so we chose as intermediate variables, the stator currents $\left(i_{\mathrm{ds} 1}, i_{\mathrm{qs} 1}, i_{\mathrm{ds} 2}, i_{\mathrm{qs} 2}\right)$, to let them follow their references values defined by the "virtual controls", finally, we compute the stator voltages controls $\left(\mathrm{V}_{\mathrm{ds} 1}, \mathrm{~V}_{\mathrm{qs} 1}, \mathrm{~V}_{\mathrm{ds} 2}, \mathrm{~V}_{\mathrm{qs} 2}\right)$ required to let the "virtual controls" converge to the desired values with regards to the stability of the associated Lyapunov function [6]-[8].

\subsection{Application of nonlinear integral backstepping control to DSIM}

In our work, we use Integral backstepping control by using both reduced and complete model of oriented induction machine (1-2).

Our objective is to synthesize the expression of the control variables $\mathrm{V}_{\mathrm{sd} 1}, \mathrm{~V}_{\mathrm{sd} 2}$ and $\mathrm{V}_{\mathrm{sq} 1}, \mathrm{~V}_{\mathrm{sq} 2}$ to let the state variables of the DSIM follow the desired references Figures 1, 2, and 3. By making a variables change, the new ones are the errors between the set points and the state variables. This control is presented in six steps shows in Figure 2, as we will show in this section [9].

\subsection{Nonlinear integral backstepping control using the reduced model}

In this part we use the reduced mathematical model (2) of the DSIM[9].

\subsubsection{First step "Speed Loop":}

This first step consists in identifying the errors $\mathbf{e}_{\mathbf{1}}$ which represent the error between real speed " $\omega$ " and reference speed ' $\omega$ "', for the electrical speed “ $\omega \mathbf{r}$ ”, we define the racking error as:

$$
e_{1}=\omega^{*}-\omega
$$

And their dynamics are given by:

$$
\begin{aligned}
& \dot{e_{1}}=\dot{\omega}^{*}-\dot{\omega} \\
& \dot{i}_{q s}^{*}=\left(i_{q s 1}+i_{q_{s 2}}\right) \text { Then the error dynamical equations are: }
\end{aligned}
$$




$$
\begin{aligned}
& \dot{e_{1}}=\dot{\omega}-b_{7} \varphi_{d r}\left(\dot{i}_{q s 1}+i_{q s 2}\right)-b_{8}-b_{9} \omega_{r} \quad V_{1}\left(e_{1}\right)=\frac{1}{2} e_{1}^{2} \\
& \text { Its derivative is: } \dot{V}_{1}\left(e_{1}\right)=e_{1} \dot{e}_{1} \quad \dot{V}_{1}\left(e_{1}\right)=e_{1}\left(\dot{\omega}-b_{7} \varphi_{d r}\left(i_{q s 1}+i_{q s 2}\right)-b_{8}-b_{9} \omega_{r}\right) \\
& i_{q s}^{*}=\frac{\omega^{*}+b_{9} \omega_{r}+b_{8}+C_{1} e_{1}}{b_{7} \varphi_{r}}
\end{aligned}
$$

With $\mathrm{C}_{1}$ is a positive constant.

The derivative of the Lyapunov function becomes: $\dot{V}_{1}\left(e_{1}\right)=-c_{1} e_{1}^{2}<0$

Since the current $\mathrm{i}_{\mathrm{qs}}$ is not a control input and is only one variable of the system with its own dynamics. We will use it to introduce the integral action, so we choose the desired dynamic behavior of the virtual control ' $\mathrm{i}_{\mathrm{qs}}{ }^{*}$ ' as following:

$$
I_{q s}^{*}=\frac{\omega^{*}+b_{9} \omega_{r}+b_{8}+C_{1} e_{1}}{b_{7} \varphi_{r}}+\lambda_{1} x_{1}
$$

with $\lambda 1$ is positive constant and $x_{1}=\int_{0}^{\tau} e_{1}(\tau) d \tau$ is the integral action brought in accordance with the following error "e". By introducing this integral in the virtual control, we ensure the convergence of tracking error to zero in steady state shows in Figure 1.

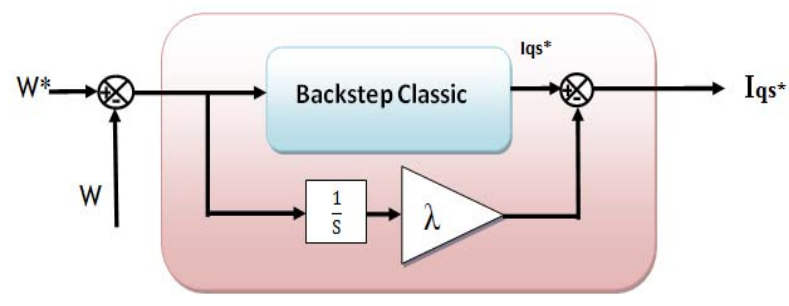

Figure 1. Integral action backstepping diagram

\subsubsection{Second step "iqs1 Current Loop":}

For this step, our goal is the replacement of the virtual current control by computing control voltages.

We define the error of the (q) axis component of the stator current and its reference:

$$
e_{2}=I_{q s}^{*}-i_{q S 1}
$$

The derivative is written as:

$$
\begin{aligned}
& \dot{e_{2}}=\dot{I}_{q S}{ }^{*}-i_{q S 1}^{*} \\
& \dot{e_{2}}=\dot{I}_{q s}^{*}+\delta_{1}-V_{q s 1} / b_{3} \quad \text { With: } \delta_{1}=\left\lfloor b_{1} i_{q s 1}+a_{1} b_{2} i_{d s 1}+a a_{1} i_{d s 2}-a_{1} d_{1} \phi_{r}\right\rfloor / b_{3} \\
& V_{2}\left(e_{2}\right)=\frac{1}{2} e_{2}^{2}
\end{aligned}
$$


Its derivative is: $\dot{V}_{2}\left(e_{2}\right)=e_{2} \dot{e}_{2} \quad \dot{V}_{2}\left(e_{2}\right)=e_{2}\left(\dot{I}_{q s}{ }^{*}+\delta_{1}-V_{q s 1} / b_{3}\right)$

For a negative error derivative e2, we must choose as the first control voltage: ${ }_{q s 1}^{*}=\left(\dot{I}_{q s}^{*}+\delta_{1}+C_{2} e_{2}\right) b_{3}$.

$\dot{V}_{2}\left(e_{2}\right)=-C_{2} e_{2}^{2}<0$ With $\mathrm{C}_{2}$ is a positive constant.

\subsubsection{Third step "iqs2 Current Loop":}

We define the tracking error as:

$$
e_{3}=I_{q s}^{*}-i_{q s 2}
$$

The derivative is written as:

$$
\begin{aligned}
& \dot{e_{3}}=\dot{I_{q s}^{*}}-\dot{i_{q s 2}} \\
& \dot{e_{3}}=\dot{I_{q s}^{*}}+\delta_{2}-V_{q s 2} / b_{3} \text { With: } \\
& \delta_{2}=\left(b_{4} i_{q s 2}+a_{1} b_{2} i_{d s 2}+a a_{1} i_{d s 1}+a_{1} d_{1} \phi_{r}\right) / b_{3} \\
& V_{3}\left(e_{3}\right)=\frac{1}{2} e_{3}^{2}
\end{aligned}
$$

Its derivative is:

$$
\begin{aligned}
& \dot{V}_{3}\left(e_{3}\right)=e_{3} \dot{e}_{3} \\
& \dot{V}_{3}\left(e_{3}\right)=-e_{3}\left(\dot{I}_{q s}{ }^{*}+\delta_{2}-V_{q s 2} / b_{3}\right)
\end{aligned}
$$

For a negative error derivative $\mathrm{e} 2$, we must choose as the second control voltage. $V_{q s 2}^{*}=\left(I_{q s}^{*}+\delta_{2}+C_{3} e_{3}\right) b_{3}$ $\dot{V}_{3}\left(e_{3}\right)=-C_{3} e_{3}^{2}<0$ With $\mathrm{C}_{3}$ is a positive constant.

\subsubsection{Step four " $\varphi d r$ Flux Loop":}

We define the tracking error as:

$$
e_{4}=\dot{\varphi}_{r}^{*}-\varphi_{d r}
$$

And its derivative with respect to time leads to:

$$
\begin{aligned}
& \dot{e}_{4}=\dot{\varphi}_{r}^{*}-\dot{\varphi}_{r} \\
& -C_{4} e_{4}=\dot{\varphi}_{r}^{*}-b_{5}\left(i_{d s 1}+i_{d s 2}\right)+b_{6} \varphi_{r} \quad i_{d s}^{*}=\left(i_{d s 1}+i_{d s 2}\right) \\
& -C_{4} e_{4}=\dot{\varphi}_{r}^{*}-b_{5}\left(i_{d s}^{*}\right)+b_{6} \varphi_{r} \\
& i_{d s}^{*}=\frac{\dot{\varphi}_{r}^{*}+b_{6} \varphi_{r}+C_{4} e_{4}}{b_{5}}
\end{aligned}
$$

with $\mathrm{C}_{4}$ is a positive constant.

The derivative of the Lyapunov function becomes: 
$\dot{V}_{4}\left(e_{4}\right)=-C_{4} e_{4}^{2}<0$

We choose the desired dynamic behaviour of the virtual control $\mathrm{i}_{\mathrm{ds}} *$ as following:

$$
I_{d s}^{*}=\frac{\dot{\varphi}_{r}^{*}+b_{6} \varphi_{r}+C_{4} e_{4}}{b_{5}}+\lambda_{2} x_{2}
$$

With $\lambda_{2}$ is positive constant and $x_{2}=\int_{0}^{\tau} e_{4}(\tau) d \tau$ is the integral action brought in accordance with the following error " $e$ " By introducing this integral in the virtual control, we ensure the convergence of the tracking error to zero in steady state.

\subsubsection{Step five "id ${ }_{s 1}$ Current Loop":}

$e_{5}=I_{d s}^{*}-i_{d s 1}$

Its derivative is written as:

$\dot{e_{5}}=\dot{I}_{d s}^{*}-\dot{i_{d s 1}}$

$\dot{e_{5}}=\dot{I}_{d s}^{*}-\delta_{3}-V_{d s 1} / b_{3}$

$\delta_{3}=\left[b_{1} i_{d s 1}+d_{1}\left(b_{5}\left(i_{d s 1}+i_{d s 2}\right)-b_{6} \phi_{r}\right)-a_{1} b_{2} i_{q s 1}-a a_{1} i_{q s 2}\right] / b_{3}$

With:

$V_{5}\left(e_{5}\right)=\frac{1}{2} e_{5}^{2}$

Its derivative is

$\dot{V}_{5}\left(e_{5}\right)=-e_{5}\left(I_{d s}^{*}-\delta_{3}-V_{d s 1}^{*} / b_{3}\right)$

For a negative error derivative e 5 , we must choose as the Third control voltage $V_{d s 1}^{*}=\left(I_{d s}^{*}-\delta_{3}+C_{5} e_{5}\right) b_{3}$ $\dot{V}_{5}\left(e_{5}\right)=-C_{5} e_{5}^{2}<0$ With $\mathrm{C}_{5}$ is a positive constant.

\subsubsection{Step Six "ids2 Current Loop":}

$$
e_{6}=\stackrel{\cdot}{I_{d s}^{*}}-i_{d s 2}
$$

Its derivative is written as: $\dot{e}_{6}=\dot{I_{d s}}{ }^{*}-\dot{i_{d s 2}}$

$$
\begin{aligned}
& \dot{e_{6}}=\dot{I_{d s}}{ }^{*}-\delta_{4}-V_{d s 1} / b_{3} \text { With: } \delta_{4}=\left[b_{4} i_{d s 2}+d_{1}\left(b_{5}\left(i_{d s 1}+i_{d s 2}\right)-b_{6} \phi_{r}-a a_{1} i_{q s 1}-a_{1} b_{2} i_{q s 2}\right]\right. \\
& V_{6}\left(e_{6}\right)=\frac{1}{2} e_{6}^{2}
\end{aligned}
$$

Its derivative is: $\dot{V}_{6}\left(e_{6}\right)=-e_{6}\left(I_{d k}^{*}-\delta_{4}-V_{d 2}^{*} / b_{3}\right)$

For a negative error derivative $\mathrm{e}_{5}$, we must choose as the fourth control voltage $V_{d s 2}^{*}=\left(\dot{I}_{d s}{ }^{*}-\delta_{6}+C_{6} e_{6}\right) b_{3}$ 
$\dot{V}_{6}\left(e_{6}\right)=-C_{6} e_{6}^{2}<0 \mathrm{With} \mathrm{C}_{6}$ is a positive constant.

5.3. Nonlinear Integral Backstepping Control Using Complete Model

In this part we use the complete mathematical model of the DSIM.

\subsubsection{First Step "w Speed Loop":}

This first step consists in identifying the error 'e1'which represent the error between real speed $\omega$ and reference speed $\omega^{*}$.

$$
\begin{aligned}
& e_{1}=\omega^{*}-\omega \\
& \dot{e}_{1}=\dot{\omega}^{*}-\frac{P^{2}}{J}\left(d_{1}\right)\left[\left(i_{q+1}+i_{q r 2}\right) \varphi_{\psi}-\left(i_{d x+1}+i_{d x 2}\right) \varphi_{q r}\right]+\frac{P}{J} C r+\frac{f C}{J} \omega, . \\
& V_{1}\left(e_{1}\right)=\frac{1}{2} e_{1}^{2}
\end{aligned}
$$

Its derivative is: $\dot{V}_{1}\left(e_{1}\right)=e_{1} \dot{e}_{1}$

$$
\begin{aligned}
& \dot{V}_{1}\left(e_{1}\right)=e_{1}\left[\dot{\omega}^{*}-\frac{P^{2}}{J}\left(d_{1}\right)\left(i_{q s 1}+i_{q s 2}\right) \varphi_{d r}+\frac{P^{2}}{J}\left(d_{1}\right)\left(i_{d s 1}+i_{d s 2}\right) \varphi_{q r}+\frac{P}{J} C r+\frac{f c}{J} \omega_{r}\right] . \\
& i_{q s}^{*}=\left(i_{q s 1}+i_{q s 2}\right) \\
& i_{q s}^{*}=\left[\dot{w}+\frac{P^{2}}{J}\left(d_{1}\right)\left(i_{d s 1}+i_{d s 2}\right) \varphi_{q r}+\frac{P}{J} C_{r}+\frac{f c}{J} \omega_{r}+k_{1} e_{1}\right]\left(\frac{J\left(L_{m}+L_{r}\right)}{P^{2} L_{m} \varphi_{d r}}\right)
\end{aligned}
$$

We will use $\mathbf{i}_{\mathbf{q}}$ * to introduce the integral action, so we choose the desired dynamic behaviour of the virtual control" $\mathbf{I}_{\mathbf{q}}{ }^{*} "$ as following: $I_{q s}{ }^{*}=i_{q s}{ }^{*}+\lambda_{3} x_{3}$ With $\mathbf{k}_{\mathbf{1}}$ is a positive constant

\subsubsection{Second Step "iqs1 Current Loop":}

The Replacement of the virtual current control by computing control voltages, we define the error of the $(\mathrm{q})$ axis component of the stator current and its reference:

$$
e_{2}=I_{q s}^{*}-i_{q s 1}
$$

Its derivative is written as: $\dot{e}_{2}=\dot{I}_{q s}^{*}-\dot{i}_{q s 1}$

$$
\begin{aligned}
& \dot{e_{2}}=\dot{I}_{q s}^{*}+\delta_{5}-V_{q s 1} \text { with: } \delta_{5}=R_{s} i_{s q 1}+\left(d_{1}\right) \frac{d \varphi_{q r}}{d t}+\omega_{s}\left[\left(L_{s}+a\right) i_{s d 1}-a i_{d s 2}+\left(d_{1}\right) \varphi_{d r}\right] \\
& \dot{e_{2}}=\dot{I}_{q s}^{*}-\left[V_{q s 1}-R_{s} i_{q s 1}-\left(d_{1}\right) \frac{d \varphi_{q r}}{d t}-\omega_{s}\left[\left(L_{s}+a\right) i_{d s 1}+a i_{d s}+\left(d_{1}\right) \varphi_{d r}\right]\right] \\
& V_{2}\left(e_{2}\right)=\frac{1}{2} e_{2}^{2}
\end{aligned}
$$

Its derivative is: $\dot{V}_{2}\left(e_{2}\right)=e_{2} \dot{e}_{2}$ and $\dot{V}_{2}\left(e_{2}\right)=e_{2}\left(\dot{I}_{q s}{ }^{*}+\delta_{5}-V_{q s 1}\right)$ 
For a negative error derivative $\mathrm{e}_{2}$, we must choose as the first control voltage. $V_{q s 1}^{*}=\left(\dot{I}_{q s}^{*}+\delta_{5}+k_{2} e_{2}\right)$ $\dot{V}_{2}\left(e_{2}\right)=-k_{2} e_{2}^{2}<0$ With $\mathrm{k}_{2}$ is a positive constant.

\subsubsection{Third Step "iqs2 Current Loop":}

We define the tracking error as:

$$
e_{3}=I_{q s}^{*}-i_{q s 2}
$$

The derivative is written as: $\dot{e_{3}}=\dot{I}_{q s}^{*}-\dot{i}_{q s 2}$

$$
\dot{e}_{3}=\dot{I}_{q s}^{*}-\delta_{6}-V_{q s 2}
$$

with

$$
\begin{aligned}
& \delta_{6}=R_{s} i_{q s 2}+\left(d_{1}\right) \frac{d \varphi_{q r}}{d t}+\omega_{s}\left[\left(L_{s}+a\right) i_{d s 2}+a i_{d s 1}+\left(d_{1}\right) \varphi_{d r}\right] \\
& V_{3}\left(e_{3}\right)=\frac{1}{2} e_{3}^{2}
\end{aligned}
$$

Its derivative is: $\dot{V}_{3}\left(e_{3}\right)=e_{3} \dot{e}_{3} \quad \dot{V}_{3}\left(e_{3}\right)=e_{3}\left(\dot{I}_{q s}^{*}-\delta_{6}-V_{s q 2}\right)$

For a negative error derivative $\mathrm{e}_{3}$, we must choose as Second control voltage: $V_{q s 2}{ }^{*}=I_{q s}^{*}+k_{3} e_{3}+\delta_{6}$ $V_{3}^{*}\left(e_{3}\right)=-k_{3} e_{3}^{2}<0$ With $\mathbf{k}_{3}$ is a positive constant.

5.3.4.Step Four " $\varphi d r$ Flux Loop":

We define the tracking error as:

$$
e_{4}=\varphi_{d r}^{*}-\varphi_{d r}
$$

And its derivative with respect to time leads to:

$$
\begin{aligned}
& \dot{e_{4}}=\dot{\varphi}_{d r}^{*}-\dot{\varphi}_{d r} \\
& \dot{e}_{4}=\dot{\varphi}_{d r}^{*}-\left[b_{5}\left(i_{d s 1}+i_{d s 2}\right)-\left(b_{6}\right) \varphi_{r d}+\omega_{g l} \varphi_{q r}\right]
\end{aligned}
$$

We make:

$$
\dot{i}_{d s}^{*}=\left(i_{d s 1}+i_{d s 2}\right) \quad i_{d s}^{*}=\left[\varphi_{r}-\omega_{g l} \varphi_{q r}+k_{4} e_{4}\right] \frac{1}{b_{5}}+\frac{1}{L_{m}} \varphi_{d r}
$$

With $\mathbf{k}_{\mathbf{4}}$ is a positive constant.

The derivative of the Lyapunov function becomes: $\quad \dot{V}_{4}\left(e_{4}\right)=-k_{4} e_{4}^{2}<0$

We choose the desired dynamic behavior of the virtual control $\mathbf{i}_{\mathbf{d s}} *$ as following:

$$
I_{d s}^{*}=i_{d s}^{*}+\lambda_{4} x_{4}
$$


With $\lambda 4$ is positive constant and $x_{4}=\int_{0}^{\tau} e_{4}(\tau) d \tau$ is the integral action brought in accordance with the following error "e". By introducing this integral in the virtual control, we ensure the convergence of the tracking error to zero in steady state.

\subsubsection{Step five "id ${ }_{s 1}$ Current Loop":}

$$
e_{5}=I_{d s}^{*}-i_{d s}
$$

Its derivative is written as: $\quad \dot{e}_{5}=\dot{I}_{d s}^{*}-\dot{i_{d s} 1}$

$$
\begin{aligned}
& \dot{e}_{5}=\dot{I}_{d s}{ }^{*}-\delta_{7}-V_{d s 1} \text { with: } \delta_{7}=R_{s} i_{d s 1}+\left(d_{1}\right) \frac{d \varphi_{d r}}{d t}-\omega_{s}\left[\left(L_{s}+a\right) i_{q s 1}-a i_{q s 2}-\left(d_{1}\right) \varphi_{q r}\right] \\
& V_{5}\left(e_{5}\right)=\frac{1}{2} e_{5}^{2}
\end{aligned}
$$

Its derivative is: $\dot{V}_{5}\left(e_{5}\right)=\frac{1}{2} \dot{e}_{5}^{2}$

$$
\dot{V}_{5}\left(e_{5}\right)=e_{5}\left(\dot{I}_{d s}^{*}-\delta_{7}-V_{d s 1}^{*}\right)
$$

For a negative error derivative $\mathrm{e}_{5}$, we must choose as the third control voltage $V_{d s 1}^{*}=\dot{I}_{d s}^{*}-\delta_{7}+k_{5} e_{5}$ $\dot{V}_{5}\left(e_{5}\right)=-k_{5} e_{5}^{2}<0 \quad$ With $\mathrm{k}_{5}$ is a positive constant.

\subsubsection{Step Six "ids2 Current Loop":}

$$
e_{6}=I_{d s}^{*}-i_{d s 2}
$$

Its derivative is written as: $\dot{e}_{6}=\dot{I}_{d s}{ }^{*}-\dot{i}_{d s 2}$

$$
\begin{aligned}
& \dot{e}_{6}=\dot{I}_{d s}{ }^{*}-V_{d s 2}+\delta_{8} \text { With: } \delta_{8}=R_{s} i_{d s 2}+d_{1} \cdot \frac{d \varphi_{d r}}{d t}-\omega_{s}\left[\left(L_{s}+a\right) i_{q s 2}+a . i_{q s 1}+d_{1} \cdot \varphi_{q r}\right] \\
& V_{6}\left(e_{6}\right)=\frac{1}{2} e_{6}^{2}
\end{aligned}
$$

Its derivative is: $\dot{V}_{6}\left(e_{6}\right)=e_{6} \dot{e}_{6} \quad \dot{V}_{6}\left(e_{6}\right)=-e_{6}\left(\dot{I}_{d s}{ }^{*}-\delta_{8}-V_{d s 2}^{*}\right)$

For a negative error derivative es, we must choose as fourth control voltage $\dot{V}_{d s 2}=\left(\dot{I}_{d s}{ }^{*}-\delta_{8}+k_{6} e_{6}\right)$ $\dot{V}_{6}\left(e_{6}\right)=-k_{6} e_{6}^{2}<0$ With $\mathbf{k}_{6}$ is a positive constant.

\subsubsection{Step seven " $p q r$ Flux Loop”:}

$$
e_{7}=\phi_{q r}^{*}-\phi_{q r}
$$

Its derivative is written as: $\dot{e}_{7}=\dot{\varphi}_{q r}^{*}-\dot{\varphi}_{q r}$ and $-k_{7} e_{7}=\dot{\varphi}_{q r}^{*}-\left[b_{5}\left(i_{q s 1}+i_{q s 2}\right)-b_{6} \varphi_{q r}-\omega_{g l}^{*} \varphi_{d r}\right]$ 


$$
\begin{aligned}
& V_{7}\left(e_{7}\right)=\frac{1}{2} e_{7}^{2} \\
& \dot{V}_{7}\left(e_{7}\right)=-k_{7} e_{7}^{2}<0 \text { With } \mathrm{k}_{7} \text { is a positive constant. }
\end{aligned}
$$

We choose as seven control vector as: $\omega_{g l}{ }^{*}=\frac{1}{\varphi_{d r}}\left[-\dot{\varphi}_{q r}+b_{5}\left(i_{d s 1}+i_{d s 2}\right)-b_{6} \varphi_{q r}-k_{7} e_{7}\right]$

$\stackrel{*}{V_{7}}\left(e_{7}\right)=-k_{7} e_{7}^{2}<0 \quad$ With $\mathbf{k}_{7}$ is a positive constant.

$$
\begin{aligned}
& V_{d s 1}^{*}=\left(\dot{I_{d s}^{*}}-\delta_{7}+k_{5} e_{5}\right) \quad V_{d s 2}^{*}=\left(\dot{I_{d s}^{*}}-\delta_{8}+k_{6} e_{6}\right) \quad V_{q s 1}^{*}=\left(I_{q s}^{*}+\delta_{5}+k_{2} e_{2}\right) \\
& V_{q s 2}^{*}=\left(\dot{I_{q s}^{*}}+\delta_{6}+k_{3} e_{3}\right) .
\end{aligned}
$$

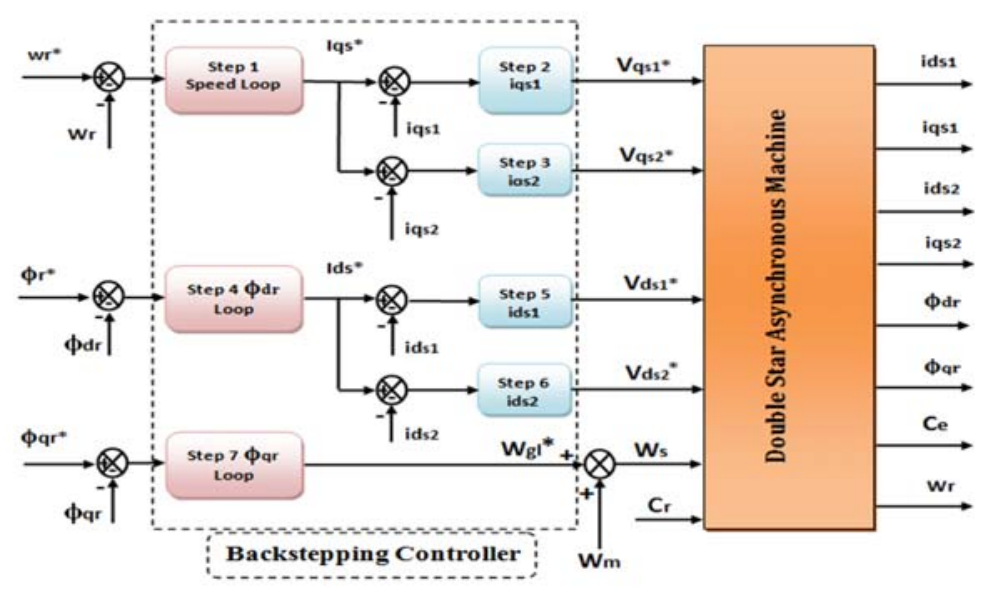

Figure 2. Backstepping diagram of double star Induction machine (DSIM) using Complete Model

\section{SIMULATION RESULTS (ON LOAD)}

The effectiveness of the Integral Backstepping control applied to DSIM with both complete and reduced models has been validated by numerical simulation (Matlab Simulink),With application of resistant

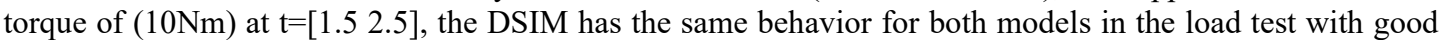
rejection of disturbance in the graph of the rotor speed, The direct and quadrature rotor fluxes $\left(\varphi_{\mathrm{dr}}, \varphi_{\mathrm{qr}}\right)$ and the two stator currents of axis (d-q) stabilize to theirs reference values.

\section{RESULTS DISCUSSION}

The rotor speed follow very well its reference value with a good rejection of disturbance even with the application of the load due to the backstepping regulation, and the integral action allowed us to maintain the static error at a value of zero Figures 3, 4, and 7. 

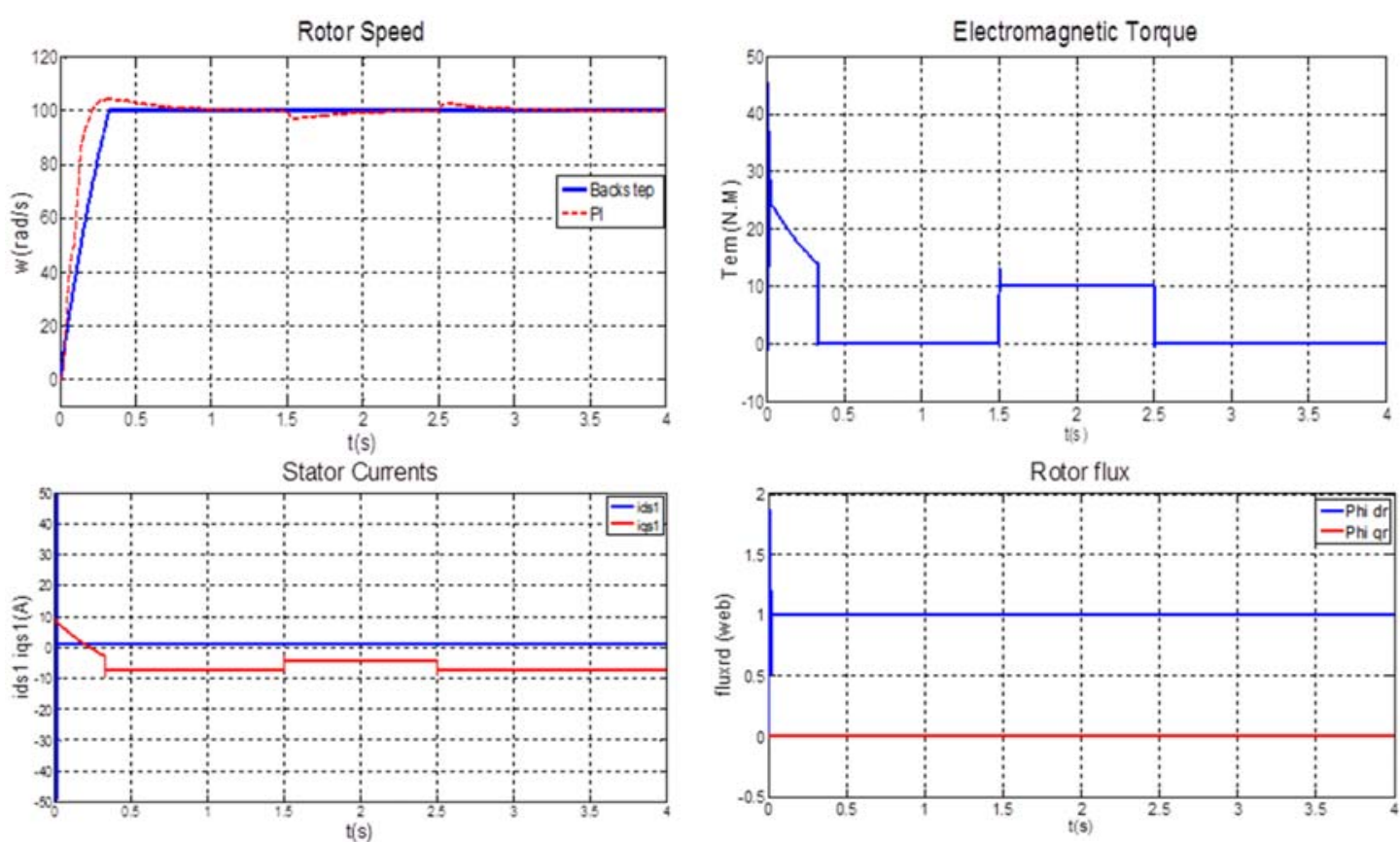

Figure 3. Reduced model performance
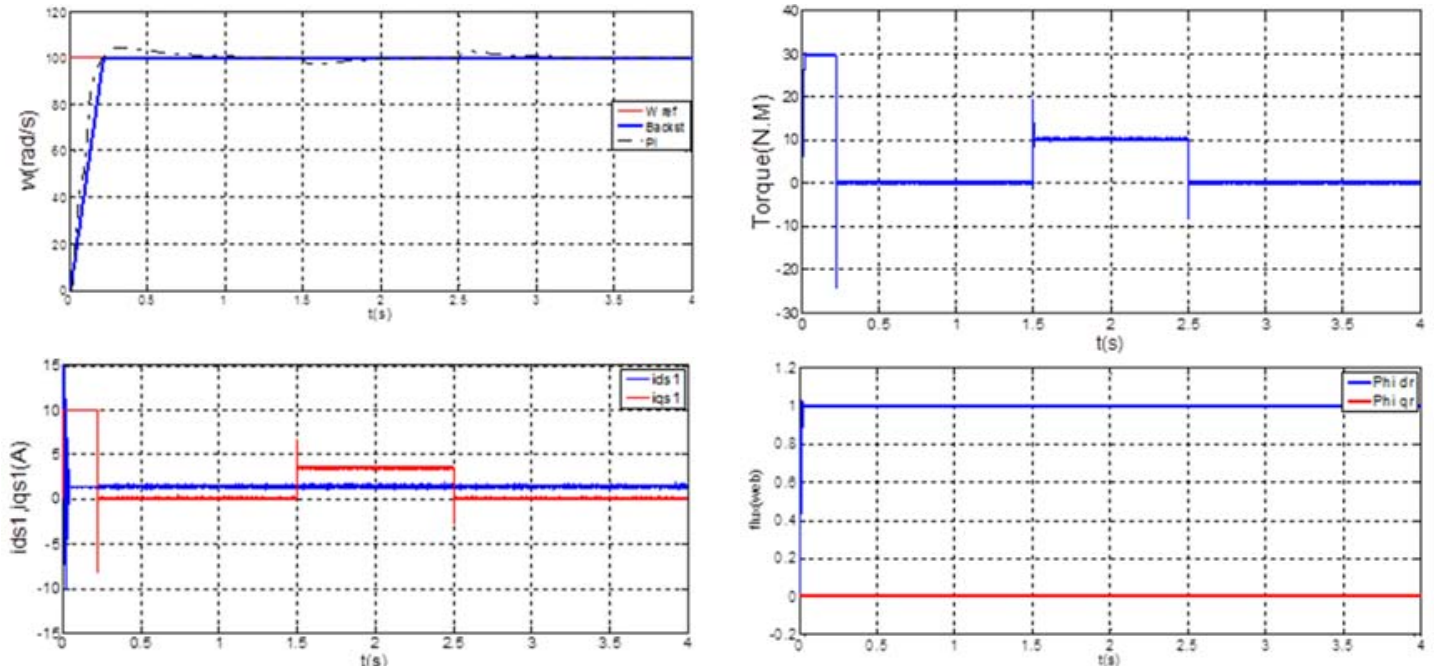

Figure 4. Complete model performances

\subsection{Robustness Test}

In this part we have increase the rotor resistance by application of the load $(R r=2 x \operatorname{Rrn})$ at time $t=[1.5-2.5] \mathrm{sec}$ in order to verifying the robustness of non-linear Integral Backstepping regulation under DSIM parameters variations, Figures 5-6 shows the responses of different variables states. 

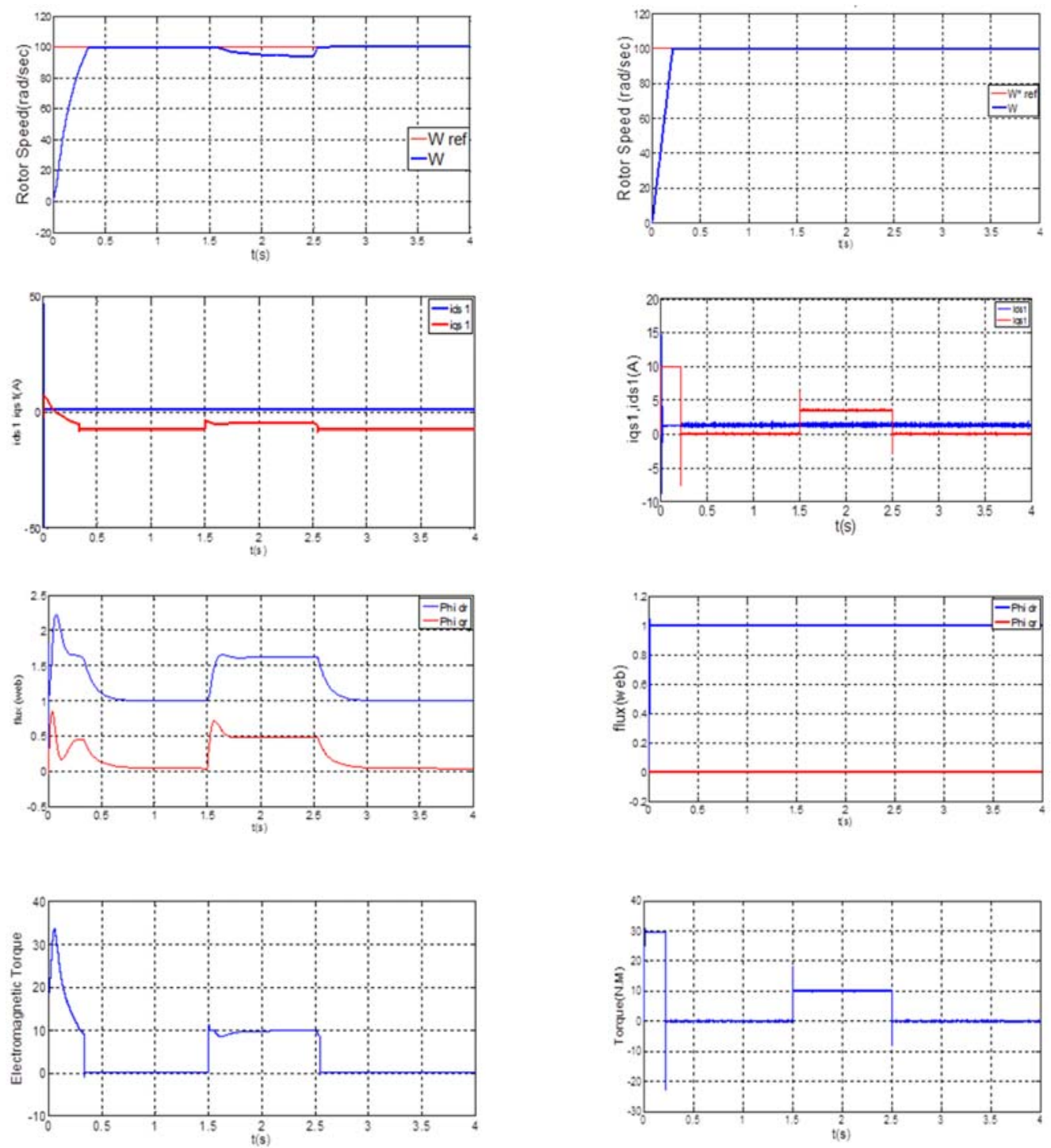

Figure 5. Reduced model robustness test with $(\mathrm{Rr}=2 \times \mathrm{Rrn})$

Figure 6. Complete model robustness test with $(\mathrm{Rr}=2 \times \mathrm{Rrn})$

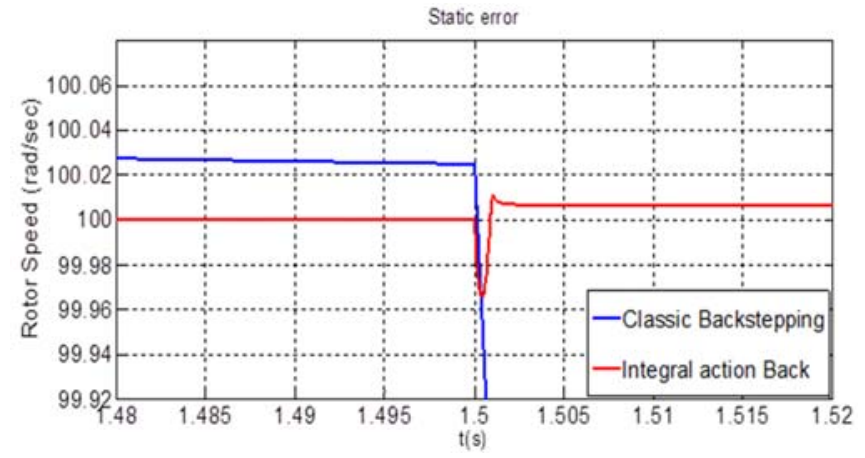

Figure 7. Static error with a reference speed $(100 \mathrm{rad} / \mathrm{sec})$ 


\subsection{Discussion of Robustness Test Results $\left(\operatorname{Rr}=\mathbf{2} \times R_{\mathrm{rn}}\right)$}

Reduced model test shown in Figure 5 prove that the decoupling between the Flux And the Torque is lost and the static error has appear because of the simplification adopted in field oriented control who makes $\left(\varphi_{\mathrm{qr}}=0\right)$ and renders this model incapable of adapting to the change of internal parameters.

Complete model test shown in Figure 6 responded well to the change of the internal parameter $\mathrm{R}_{\mathrm{r}}$, because, the expression of ' $\omega_{\mathrm{gl}}$ ' in the complete model is derived from the regulation loop with backstepping using the ' $\varphi_{\mathrm{qr}}$ flux loop', that's allowing to take into consideration the variation of ' $\varphi_{\mathrm{qr}}$ ' which depend to ' $R_{\mathrm{r}}$ ' and $\omega_{\mathrm{gl}}$ with: $\left(\omega_{\mathrm{gl}}=\omega_{\mathrm{s}}-\omega_{\mathrm{r}}\right)(1)$, intervenes so as to maintain this coupling constant.

\section{CONCLUSIONS}

Several researchers based on the reduced model of the double-star asynchronous machine in their works, in this paper we presented a nonlinear integral backstepping of the DSIM based on field oriented control principle followed by a comparative robustness test between reduced and complete models of DSIM. Firstly we saw that the non linear integral backstepping control of the DSIM gave satisfactory results in comparison with the PI vector regulator in terms of response time, static error and disturbance rejection, we can see also that the integral action in Figures 1-7 allow us to highly reduce the static speed error.

In the analysis of the results of the empty and load test, with the nominal parameters we obtained satisfactory and quasi identical simulation results for the two models. But the results of the robustness test obtained, proved the high performance by using complete model in control against the reduced model, it can be seen that all the state vectors converged to their desired real values in Figures 5 and 6 with a total rejection of disturbance and maintaining of the decoupling between the flux and the torque. We already know that the internal parameters and especially the rotor resistance in practice increases during operation of the machine and if we looking for a model that corresponds to the DSIM in real operation of course with the simplifications already quoted in 'paragraph 3', This leads us to opt for the complete model.

\section{NOMENCLATURE}

s: Index Stator.

r: Index Rotor.

$\mathbf{V}_{\text {ds1 }}, \mathbf{V}_{\mathbf{q s 1}}, \mathbf{V}_{\mathbf{d s 2},}, \mathbf{V}_{\mathbf{q s 2}}$ : Stator voltages d-q axis components.

$\mathbf{i}_{\text {ds1 } 1}, \mathbf{i}_{\mathbf{q s} 1}, \mathbf{i}_{\text {ds2 } 2}, \mathbf{i}_{\mathbf{q} s 2}$ : Stator currents d-q axis components.

$\mathbf{R}_{\mathbf{~} 1}, \mathbf{R}_{\mathbf{s} 2}$ : Stators resistances.

$\varphi_{\mathrm{dr}}, \boldsymbol{\varphi}_{\mathrm{qr}}$ : Rotor flux d-q axis components.

$\mathbf{R}_{\mathbf{r}}, \mathbf{R}_{\mathbf{r n}}$ : Rotor resistance, nominal resistance

$\mathbf{L}_{\mathbf{s} 1}, \mathbf{L}_{\mathbf{s} 2}$ : Stators inductances.

Lr: Rotor Inductance.

Lm: Mutual inductance.

a) Reduced Model Constants are: $\mathrm{C}_{1}=\mathrm{C}_{4}=\mathrm{C}_{6}=10000, \mathrm{C}_{2}=\mathrm{C}_{3}=\mathrm{C}_{5}=1000, \lambda_{1}=0.698, \lambda_{2}=10$.

b) Complete Model Constants are: $\mathrm{k}_{1}=1500, \mathrm{k}_{2}=\mathrm{k}_{3}=3000, \mathrm{k}_{4}=20000, \mathrm{k}_{5}=\mathrm{K}_{6}=\mathrm{k}_{7}=1000, \lambda_{3}=0.001, \lambda_{4}=0.1$.

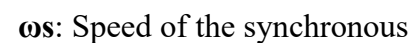

reference frame.

$\omega$ : Rotor electrical angular speed.

$\omega g l:$ Slip frequency.

$\mathbf{J}$ : Moment of inertia.

P: Number of pole pairs.

$\mathbf{\Omega}$ : Mechanical speed.

$\mathbf{T}_{\mathbf{e m}}$ or $\mathbf{C}_{\mathbf{e}}$ : Electromagnetic torque.

TI or Cr: Load torque. fc: Friction coefficient.

\section{REFERENCES}

[1] Paulo Dainez,Daniel Glose, "Modeling and Parameter Identification of Double-Star Induction Machines" PRZEGLĄD ELEKTROTECHNICZNY (Electrical Review), ISSN 0033-2097, R. 88 NR 3b/2012.

[2] R. Bojoi, F. Farine, F. Profumo, and A. Tenconi, "Dual-three phaseinduction machine drives control - a survey," IEEE Trans. on IndustryApplications, vol. 126, no. 4, pp. 420-429, 2006

[3] E. Merabet, R. Abdessemed, H. Amimeur and F. Hamoudi'"' Field Oriented Control of a Dual Star Induction Machine Using Fuzzy Regulator"iceeac-dz.org.

[4] Radhwane Sadouni, Abdelkader Meroufel "Indirect Rotor Field-oriented Control (IRFOC) of a Dual Star Induction Machine (DSIM) Using a Fuzzy Controller" in Acta Polytechnica Hungarica.

[5] G.R. Arab Markadeh, J. Soltani, N.R. Abjadi, M. Hajian, "Sensorless Control of a Six-Phase Induction Motors Drive Using FOC in Stator Flux Reference Frame", International Journal of Mechanical Aerospace Industrial Mechatronic and Manufacturing Engineering, vol. 3, no. 10, 2009.

[6] Laoufi A.,Hazzab A, Bousserhane I.K, Rahli M, 'Direct Field-Oriented Control using Backstepping Technique for Induction Motor Speed Control" in International journal of Applied Engineering Research, ISSN 09734562,Vol.1, pp.37-50, 2006.

[7] Anissa Hosseyni, Ramzi Trabelsi, Atif Iqba, Med Faouzi Mimouni "Backstepping Control for a Five-Phase Permanent Magnet Synchronous Motor Drive" International Journal of Power Electronics and Drive System (IJPEDS)Vol. 6, No. 4, pp. 842 852 ISSN: 2088-8694, December 2015.

[8] O. Boughazi, A. Boumedienne, A. Omari, "An Efficiency Backstepping Control without Speed Sensor applied to the Induction Motor Voltage Supplied” (EEA) Vol.62| $\mathrm{Nr}^{\circ}: 1 \mid 2014$. 
[9] Mohamed Horch, Abdelmadjid Boumediene, Lotfi Baghli, "Nonlinear Integral Backstepping Control for Induction Motor drive with Adaptive Speed Observer using Super Twisting Strategy". In the scientific journal of Electrotehnică, Electronică, and Automatică (EEA) Vol. $64\left|\mathrm{Nr}^{\circ}: 1\right| 2016$.

[10] Nadia Akkari, Abdelaziz Chaghi, And Rachid Abdessemed "' Speed Control of Doubly Star Induction Motor Using Direct Torque DTC Based to on Model Reference Adaptive Control (MRAC)" in International Journal of Hybrid Information Technology, Vol.7, No.2, 2014.

[11] A. Massoum, A. Meroufel, A. Bentaallah, "Sliding Mode Speed Controller for Vector Controlled Double Star Induction Motor" PRZEGLAD ELEKTROTECHNICZNY (Electrical Review), ISSN 0033-2097, R. 88 NR 3b/2012.

[12] Meroufel, S. Massoum, A. Bentaallah, P. Wira, F.Z. Belaimech, A. Massoum, "Double star induction motor direct torque control with fuzzy sliding mode speed controller", Rev. Roum. Sci. Techn-Electrotechn and Energ., vol. 62, no. 1, pp. 31-35, 2017.

\section{APPENDIX}

$\mathrm{P}=4.5 \mathrm{~W}, \mathrm{~V}=220 \mathrm{v}, \mathrm{I}=6.5 \mathrm{~A}, \mathrm{~W}_{\mathrm{n}}=2840 \mathrm{rpm}, \mathrm{R}_{\mathrm{r}}=2.12 \Omega, \mathrm{Ls} 1=\mathrm{L}_{\mathrm{s} 2}=0.011 \mathrm{H}, \mathrm{R}_{\mathrm{s} 1}=\mathrm{R}_{\mathrm{s} 2}=1.86 \Omega$, $\mathrm{L}_{\mathrm{r}}=0.274 \mathrm{H}, \mathrm{L}_{\mathrm{m}}=0.3672 \mathrm{H}, \mathrm{P}=1, \mathrm{~J}=0.0625 \mathrm{~kg} \cdot \mathrm{m}^{2}, \mathrm{fc}=0.008 \mathrm{~N} \cdot \mathrm{m} . \mathrm{s} / \mathrm{rd}$.

\section{BIOGRAPHIES OF AUTHORS}

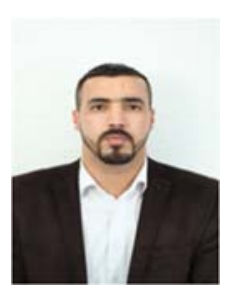

Abdallah Abden was born in Bechar (Algeria), on August 8, 1980. He received Electrical engineering degree, and Master II degree in Bechar University, Bechar, Algeria, in 2006 and 2013 respectively, Currently he is a PHD student at the same university; he is a member of Control analysis and optimization of Electro-energy systems laboratory. His main research activity is focused on control, observer and estimator of electric machine drive systems.Professional e-mail: abdenabd08@gmail.com

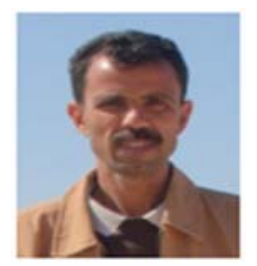

Abdelkrim Boucheta was born in Bechar, Algeria, in 1971. He received his BS degree and M.S. degree in electrical engineering from the Electrical Engineering Institute of the University Center of Bechar, in 2001 and 2006, respectively. He received the PhD degree in Electrical Engineering from the University of Djilali Liabes Sidi-Belabbes (Algeria), in 2010, He is currently Professor of electrical engineering at University of Bechar, His areas of interest are modern and adaptive control and their application in linear electric drives control.

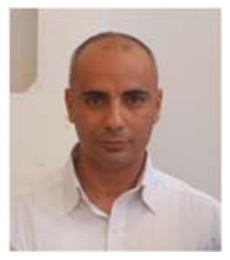

Othmane Boughazi was born in Bougtob, El-Bayadh, Algeria, in 1977. He received the Engineer degree in Electro-technic, and the Magister degree from Bechar University, Bechar, Algeria, in 2006 and 2010 respectively. He received the $\mathrm{PhD}$ degree in electrical engineering from the University of Bechar (Algeria), in 2016. His main research activity is focused on electric machine drive systems, power electronics and Process control.

Professional e-mail: othmaneboughazi@yahoo.fr

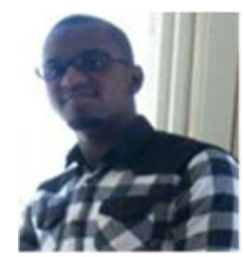

Azeddine Baghdadi was born in BECHAR (Algeria), on November 26, 1990. He received Electrical licence and master degree in 2012 and 2014 respectively. Currently he is a PHD student at university of Sidi-bel-abbes; He is a member of Control and Electrical Power System Laboratory, University of Sidi-Bel-Abbes. His areas of interest are electrical machines drives, process control, estimation and observation techniques to electrical drive systems. E-mail: azeddine.beghdadi@yahoo.fr.

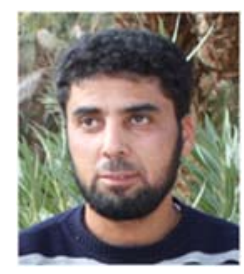

Bouserhane Ismail Khalil was born in Bechar, Algeria, in 1976. He received his BS degree in electrical engineering from the Electrical Engineering Institute of the University Centre of Bechar in 2000.He received the M.S. degree and the PhD degree in Electrical Engineering from the University of Sciences and Technology of Oran (Algeria), in 2003 and 2008, respectively, $\mathrm{He}$ is currently Professor of electrical engineering at University of Bechar, Bechar, Algeria. His areas of interest are modern control techniques and their application 